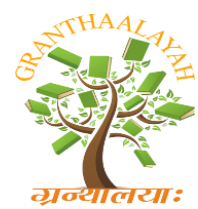

INTERNATIONAL JOURNAL OF RESEARCH GRANTHAALAYAH

A knowledge Repository

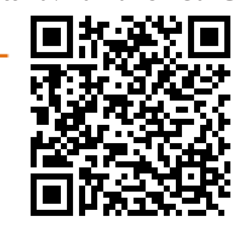

Social

\title{
FAMILY INTERACTION PATTERN AND CO-DEPENDENCY IN SPOUSES OF ALCOHOL DEPENDENCE IN COMPARISON WITH NORMAL CONTROL
}

\author{
Dr. M. Senthil ${ }^{* 1}$ \\ ${ }^{* 1}$ Psychiatric Social Worker, Deptartment of Psychiatric Social Work, National Institute of \\ Mental Health and Neuro Sciences (NIMHANS), Bangalore-29, INDIA
}

\begin{abstract}
Alcoholism is destructive to those closest to the alcoholic, and it affects families in several different ways. Many times, rehabilitating an alcoholic is only one part of the process of healing a home. Family members may also need support and counseling. Families with alcohol dependent suffer from a range of problems. Spouses can live in constant conflict. The present study aim was to compare the family interaction and codependency in spouses of alcohol dependence in comparison with normal control. It was a cross sectional study and purposive sampling method was used. Sample consisted of 30 spouses of individuals with alcohol dependence and 30 spouses of normal individuals. Alcohol Dependence Questionnaire was administered on the patient and General Health Questionnaire was administered on spouses for screening purpose. Socio-demographic data sheet, Family Interaction Pattern scale, and Co-dependency Scale were administered on the spouse of both groups. The data was analyzed using SPSS.16. The result revealed that spouses of individuals with alcohol dependence Syndrome had significantly higher scores in Family Interaction Pattern Scale; especially in the domains of reinforcement and role as compared to spouses of normal individuals. It also suggested that the level of codependency was significantly higher to the spouses of individuals with Alcohol Dependence Syndrome as compared to spouses of normal individuals.
\end{abstract}

Keywords:

Family Interaction Pattern, Co-Dependency, Spouses, Alcohol dependence.

Cite This Article: Dr. M. Senthil, "FAMILY INTERACTION PATTERN AND CODEPENDENCY IN SPOUSES OF ALCOHOL DEPENDENCE IN COMPARISON WITH NORMAL CONTROL" International Journal of Research - Granthaalayah, Vol. 4, No. 2 (2016): 121-128.

\section{INTRODUCTION}

Alcoholism and substance dependence problem no longer remains a source of problem limited not only to the alcohol dependence person; rather it usually becomes a continuous source of 
stress and suffering to all those people who are closely associated with the alcohol dependence person especially to the alcohol dependence spouse. Problematic alcohol use can have a particular impact on the family, its structures and functions. Alcohol dependence has been regarded as family and social disease because often causal factors of alcoholism are embedded in the family systems of the dependent individuals. Alcoholism has excessively negative effects on the marital lives of the people with alcohol dependence. Spouses of alcohol dependent persons may have feelings of hatred, self-pity, avoidance of social contacts, may suffer exhaustion and become physically or mentally ill. Very often the spouse has to perform the roles of both parents. Family responsibilities shift from two parents to one parent. As a result, the non-alcoholic parent may be inconsistent, demanding, and often neglect the children. Having financial difficulties is another issue that families of alcoholics have to deal with. The codependency term used to refer to family members affected by or influencing the behavior of the substance abuser. Related to the term enabler, which is a person who facilitates the abusers addictive behavior (e.g., providing drugs directly or money to buy drugs). Enabling is also unwillingness of a family member to accept substance dependence as a medical- psychiatric disorder or to deny that person is abusing a substance. Codependency a concept widely employed among mental health professionals treating individual diagnosed with substance use disorder and their families has been advanced to explain the deleterious effects of alcoholism on the family in particular and on spouses and children of alcohol dependence person particular. The term codependent is not the primary alcoholic's but there is a person involved in an intimate relationship with an alcohol dependent person who engage in denying, ignoring, tolerating, and enabling even encouraging the alcohol dependent person in his or her destructive drinking (Cermak, 1986; Greenleaf, 1984; schutt, 1985). The codependency is a significant psychological and behavioral disturbance that has traditionally gone undetected by the mental health professionals providing treatment for alcohol and drug addiction. Most of the spouses of alcohol dependent exhibit characteristics' of the syndrome to at least some degree. These characteristics include enabling, ignorance about the nature of alcohol dependence, denial, irrational reliance on control, poor se elf image, and stress related illness. Treatment of the codependence is essential not only because of its inherent value to the spouses, but of its importance to the alcohol dependence patient's rehabilitation. Through treatment the enabling system can be dismantled, boundaries clarified, and self-esteem enhanced. Treatment for the codependence persons is most effective when it is conducted in a group format and supplemented by didactic presentations and the patient's participation in the self-help community. The presence of individual with alcohol dependence in the family affects various aspects of family like leisure time and activities, family and social relationship and finances. Although the whole family is affected due to the presence of an individual with alcohol dependence in the family, most researchers have focused on the effect on wives who often fail to recognize the degree of their own pain. Their energies become centered on the individual with alcohol dependence which leads to the development of codependence. Their own personal needs, creativity and sexual and aggressive urges are suppressed. These processes block the growth and development. In the cognitive, emotional and spiritual aspects of the individual, and over period of time, the codependent spouses may become prone to stress related diagnosable psychiatric disorders. The development of codependence is however influenced by many factors including available healthy family functioning (Cobb, 1976). Spouses of alcohol dependent are affected on many different levels. Several studies have shown that spouses of alcohol dependent often presents significant rates of mental and physical problems, communication problem, low social activity and poor marital satisfaction.( Moos et al, 1990). 
The present study was to examine the difference in the perception of family interaction pattern and co-dependency among spouses of alcohol dependence and normal control.

\section{METHODOLOGY}

The present study consisted of 60 samples, among which 30 participants from the spouses of with alcohol dependence and 30 participants from the normal control. Purposive sampling techniques were used and data collected from outpatient and inpatient department of Central Institute of Psychiatry (CIP), Ranchi. Patients were selected as per ICD -10 DCR criteria. Tools: Socio- demographic data, GHQ-12, Severity of Alcohol Dependence Questionnaire, Family Interaction Pattern Scale and Spann ficher codependency scale were used.

\section{RESULTS}

Table 1: Socio demographic variables of spouses of alcohol dependence and normal control

\begin{tabular}{|c|c|c|c|c|c|c|}
\hline \multirow{2}{*}{\multicolumn{2}{|c|}{ Variable }} & \multicolumn{2}{|l|}{ Spouses of } & \multirow[b]{2}{*}{$\mathrm{X}^{2} / \mathrm{t}$} & \multirow[b]{2}{*}{$D f$} & \multirow[b]{2}{*}{$\mathbf{p}$} \\
\hline & & $\begin{array}{l}\text { Alcohol } \\
\text { Dependence } \\
\text { n=30 }(\%)\end{array}$ & $\begin{array}{l}\text { Normal } \\
\text { control } \\
\mathbf{n}=\mathbf{3 0}(\%)\end{array}$ & & & \\
\hline \multirow{2}{*}{ Income of family } & lower & $18(60.0)$ & $16(53.3)$ & \multirow{2}{*}{.271} & \multirow{2}{*}{1} & \multirow{2}{*}{.795} \\
\hline & middle & $12(40.0)$ & $14(46.7)$ & & & \\
\hline \multirow{2}{*}{ Type of Family } & nuclear & $23(76.7)$ & $22(73.3)$ & \multirow{2}{*}{.089} & \multirow{2}{*}{1} & \multirow{2}{*}{1.000} \\
\hline & joined & $7(23.7)$ & $8(26.7)$ & & & \\
\hline \multirow{2}{*}{$\begin{array}{l}\text { Education } \\
\text { Spouse }\end{array}$} & Illiterate & $14(46.7)$ & $4(13.3)$ & \multirow{2}{*}{7.937} & \multirow{2}{*}{1} & \multirow{2}{*}{$.010^{*}$} \\
\hline & Literate & $16(53.3)$ & $26(86.7)$ & & & \\
\hline \multirow{3}{*}{$\begin{array}{l}\text { Occupation of } \\
\text { Spouse }\end{array}$} & Housewife & $29(96.7)$ & $25(83.3)$ & \multirow{3}{*}{3.296} & \multirow{3}{*}{2} & \multirow{3}{*}{.226} \\
\hline & Labourer & $1(3.3)$ & $3(10.0)$ & & & \\
\hline & Govt. Service & $0(0)$ & $2(6.7)$ & & & \\
\hline \multirow{2}{*}{ Religion } & Hindu & $18(60.0)$ & $18(60.0)$ & \multirow{2}{*}{.000} & \multirow{2}{*}{1} & \multirow{2}{*}{1.000} \\
\hline & Non Hindu & $12(40.0)$ & $12(40.0)$ & & & \\
\hline \multicolumn{2}{|c|}{ Age of caregivers (In Years) } & $36.46 \pm 7.33$ & $37.76 \pm 7.06$ & -.699 & 58 & .487 \\
\hline
\end{tabular}

Table (1) shows comparison of the income of family, type of family, education of spouse, occupation of spouse, religion and age of spouses of persons with alcohol dependent and normal control. This table indicates that spouses of alcohol dependence patients were significantly less educated $(\mathrm{p}<.05)$ as compare to normal controls. However there is no significant difference found in income of family, type of family, occupation of spouse, religion and age of spouse between these two groups. And also this table shows that most of the spouses of alcohol dependence patients were from lower socioeconomic status, nuclear family, house wife's and belonged to Hindu religion. The age of spouses of alcohol dependent patients were $36.46 \pm 7.33$ years. 
Table 2: Comparisons of scores of family interaction pattern scale between spouses of alcohol dependent individuals and individuals of normal control group

\begin{tabular}{|c|c|c|c|c|}
\hline \multirow{3}{*}{$\begin{array}{l}\text { Scales (Domains of Family Interaction } \\
\text { Pattern Scale) }\end{array}$} & \multicolumn{2}{|l|}{$\begin{array}{l}\text { Group } \\
\mathrm{N}=60\end{array}$} & \multirow{3}{*}{$\begin{array}{l}\text { t Value } \\
(d f=58)\end{array}$} & \multirow{3}{*}{$p$} \\
\hline & $\begin{array}{l}\text { Alcoholic } \\
(n=30)\end{array}$ & $\begin{array}{l}\text { Normal } \\
(n=30)\end{array}$ & & \\
\hline & Mean \pm S.D. & Mean \pm S.D. & & \\
\hline Reinforcement & $23.20 \pm 5.15$ & $20.56 \pm 3.86$ & 2.238 & $.029 *$ \\
\hline Social support system & $29.10 \pm 4.67$ & $29.30 \pm 4.99$ & -.160 & .873 \\
\hline Role & $60.53 \pm 12.08$ & $54.63 \pm 7.69$ & 2.256 & $.028 *$ \\
\hline Communication & $59.90 \pm 13.58$ & $58.30 \pm 8.99$ & .538 & .593 \\
\hline Cohesion & $35.80 \pm 9.42$ & $33.13 \pm 5.08$ & 1.364 & .178 \\
\hline Leadership & $42.06 \pm 8.44$ & $39.53 \pm 7.62$ & 1.220 & .227 \\
\hline Total & $45.41 \pm 2.47$ & $36.20 \pm 2.35$ & 1.323 & .206 \\
\hline
\end{tabular}

$*$ Significant $\mathrm{p}<.05$

Table (2) shows comparison between spouses of persons with alcohol dependence and spouses of normal individuals on total score as well as various domains of Family Interaction Pattern Scale (Bhatti et al., 1986) like reinforcement, social support system, role, communication, cohesion, and leadership. It reveals that the spouses of alcohol dependence patients had scored significantly higher on reinforcement and role domains of Family Interaction Pattern Scale compared to spouses of normal controls $(\mathrm{p}<.05)$. There were no differences on Social support system, Communication, Cohesion, leadership and total score of family interaction pattern scale between the two groups.

Table 3: Comparison of codependency of the spouses of alcohol dependent and normal controls

\begin{tabular}{|c|c|c|c|c|}
\hline \multirow{3}{*}{$\begin{array}{l}\text { Scores Obtained by Spouses of Two Groups } \\
\text { in Codependency Scale }\end{array}$} & \multicolumn{2}{|l|}{$\begin{array}{l}\text { Group } \\
\mathrm{N}=60\end{array}$} & \multirow{3}{*}{$\begin{array}{l}\text { t } \\
\text { Value } \\
(d f=58)\end{array}$} & \multirow{3}{*}{$p$} \\
\hline & $\begin{array}{l}\text { Alcoholic } \\
(n=30)\end{array}$ & $\begin{array}{l}\text { Normal } \\
(n=30)\end{array}$ & & \\
\hline & Mean \pm S.D. & Mean \pm S.D. & & \\
\hline Codependency Score & $55.60 \pm 12.62$ & $47.03 \pm 9.49$ & 2.971 & $.004 * *$ \\
\hline
\end{tabular}

** Significant $\mathrm{p}<0.01$

Table (3) shows comparison of the level of co-dependency between spouses of individuals with alcohol dependence and spouses of normal individuals. It reveals that spouses of alcohol dependent patients had significantly high score as compare to spouses of normal individuals.

\section{DISCUSSION}

\section{DISCUSSION OF SOCIODEMOGRAPHIC VARIABLES}

In the present study, the sample size was 60 , out of which 30 were spouses of individuals with alcohol dependence, and 30 were spouses of normal individuals. The similar kinds of studies were done by Singh \& Kumar (2007) and Singh et al (2009) respectively. In the present study spouses of alcohol dependence were mostly illiterate $[n=14(46.7 \%)]$. The mean age of spouses 
of alcohol dependence patients was $36.46 \pm 7.33$ years. Whereas patients' mean age was $41.96 \pm 7.46$ years and mean age of onset of taking alcohol was $31.86 \pm 8.45$ years. Result also revealed that the mean duration of taking alcohol was $10.00 \pm 5.62$ years.

\section{FAMILY INTERACTION PATTERN IN SPOUSES OF INDIVIDUAL WITH ALCOHOL DEPENDENCE}

Families with alcohol dependent member/s have some uniqueness in terms of interpersonal relationship style and quality and general climate of the family. Earlier Steinglass (1980) postulated a life history model to understand how these families get along with problematic drinking behavior of their fellow member/s or how family system in general reaches a the 'homeostasis'. He found that in those families chronic alcoholism to one or more members tends to produce distortions in the normative family life cycle. The family is an example of a dynamic system that changes over time as membership changes, individuals change and develop, relationships change, and the family's context changes. A family system is interpretable only when its many multiple components are understood-the multiple components include the individual family members, the relationships between them, the family's relationships with its ecological context, the family's history (multigenerational and experience of events), and the host of internal and external forces for developmental change (Minuchin, 1974). Frankenstein et al (1985) showed that alcohol dependent individuals, after having alcohol tend to get involved in arguments and conflicts with their spouses and the longitudinal interactional pattern between those people and their spouses tend to become strained. Earlier Gorad (1971) examined areas like marital interactional dynamics, roles, expectations and patterns, especially in relation to alcohol dependence of married males, show a high degree of blaming, competition for dominance, responsibility avoidance by those addicted persons and presence of negative emotion and affect in the interactional and communicational pattern between alcohol dependent persons' and their spouses. He also found that in alcoholic families both the alcohol dependent person and his spouse are highly competitive and less cooperative to each other than normal families. Rychtarik et al (1989) had found that married males with dependence to alcohol tended to present their marriage in an unrealistically favourable manner and report that drinking has not caused impairment in their marriages, whereas their spouses would report significant marital discord as well as faulty interaction between them and their alcohol dependent husbands. The poor family interaction and family support can have deep rooted impact on the prognosis of alcohol dependence syndrome which was seen by previous researchers (Suman \& Nagalakshmi, 1995; Jacob \& Seilhamer, 1989; Akhito et al., 2003).

In present study, it was also observed that spouses of alcohol dependent individuals' have problems in all areas of 'family interaction pattern measuring instrument', i.e. Family Interaction Pattern Scale (FIPS) (Bhatti et al., 1986). The present study indicates that as per spouses' opinion significant dysfunction has been prevailing in various areas pertaining to family interaction pattern in the families with persons with alcohol dependence. The present study in this way also consistent to previous studies that in alcohol dependent families' interaction pattern is either erroneous or inadequate in comparison to normal families. In present study author had seen that spouses of alcohol dependent individuals had scored significantly higher than the spouses of normal people. This phenomenon could be explained by the rationale that these people are not getting adequate and desirable support from their partners and this way their 
expectations from partners tend to remain unfulfilled which might have caused this difference. In those families several family problems that are likely to co-occur with alcohol dependence, e.g., incidents of violence, conflict and low relationship satisfaction, economic and legal hassles, and under care of children, communicational problems, shrinking of social networks, etc. Communication in such family may be characterized as highly critical, involving considerable amounts of nagging, judgments, blame, complaints, and guilt (Halford \& Osgarby, 1993). Families of individuals with alcohol use disorders are often characterized by conflict, chaos, communication problems, unpredictability, inconsistencies in messages to children, breakdown in rituals and traditional family rules, emotional and physical abuse (Connors et al., 2001). In present study more or less same kind of picture has been observed, as there was a significant difference in the scores in various sub-areas of Family Interaction Pattern Scale (Tool used for measuring family interaction) between the wives of alcohol dependent persons and wives of normal persons. The demographic variable 'family type', (i.e. joint family or nuclear family) has some influence in family interaction. Nuclear families were found to have better family interaction than joint families- which was noted in present study. It can be explained as in nuclear families number of family members is relatively smaller than joint families, in nuclear families interactional dynamics among members is relatively simpler than joint families as in nuclear families numbers of various sub-systems are lesser, stratification among members or gradation among members are not strongly done like joint families, chances of pathological conditions like 'triangulation', 'alliance', etc are lesser in nuclear families, family rules, regulations and rituals are not so rigid in nuclear families, etc (Tamura \& Lau, 1984; Wolin \& Bennet, 1984).

\section{CO DEPENDENCY IN SPOUSES OF INDIVIDUAL WITH ALCOHOL DEPENDENCE}

The study shows that there is a significant negative correlation between the total score of family interaction measuring instrument i.e., Family Interaction Pattern Scale and Codependency (Score of Span-Fischer Co-dependency Scale) in study group (i.e., spouses of alcohol dependent individuals). It confers that if sense of co-dependency is found to be high if family interaction is low and vice versa. Codependency means the relationship patterns, with two people meeting each other's needs in dysfunctional ways (O'Brien \& Gaborit, 1992). Fischer et al (1991) defined codependency as: "a dysfunctional pattern of relating to others with an extreme focus outside of oneself, lack of expression of feelings \& personal meaning derived from relationship with others". According to Wright \& Wright (1991) codependency is a personality syndrome closely akin to addictive love. These authors presented an alternative point of view that focuses on the characteristics of codependent relating rather than the characteristics of the codependent person, arguing that codependency may be either endogenous or exogenous. They tried to discuss various angles related to co-dependency especially putting it under the blanket of personality predisposition and they concluded that the two assessment approaches are complementary rather than contradictory. When each person has healthy intrapersonal relationship characteristics, features such as personal accountability for self in interaction, an openness to vulnerability while also being self-protective, high esteem for self from within, a desire to be interdependent, a maturity for own age level, and responsibility for behaviors, thoughts, emotions, and desires can be observed and when a person's interactional ability is said to be problematic if does not have those healthy interpersonal characteristics. When any of these areas of intrapersonal relationship characteristics are less than adequate, are over- or under-functioning, a less than adequate pattern 
of interpersonal interaction is likely to develop. For example, a person who never wants to be alone or who always wants to be isolated and alone will have difficulty developing appropriate levels of interdependency. Co-dependency is not a pattern, but instead patterned interactions of Painful dependence upon compulsive behaviors and approval of others. The concept "Patterned interactions" implies reciprocity, circular causality and circularity. It connotes interactions between an individual and the compulsive behaviors, interactions between two or more individuals and the organization of family interactions around implicit rules and roles that help members survive the emotional pain and stress they are experiencing. It requires that accommodations in relationships take place. The inclusion of interactions is crucial for family systems theory to apply.

The interpersonal dynamics and interpersonal dependency have been given paramount importance in systemic approach of understanding family pathology and family. One goal of family systems therapists is to help individuals and families to obtain a balance of forces within the system (Kerr, 1981). Co-dependent individuals and families' recognize the ways that their system is out of balance. This is done by examining the interactive patterns of behavior-rules governing a family's interactions, roles individuals play and that the family system allows, and how accommodation and reorganization have occurred as a way of maintaining the family system. Family members can be given opportunities to practice basic family communication and social skills. This allows them a chance to learn how to express their needs and feelings (e.g., anger, fear, hopelessness to) one another in appropriate ways. In present study the researcher also found that compared to the wives of normal males, wives of alcohol dependent males' have shown significantly higher level of co-dependency. This way finding of present study regarding co-dependency is consonance with previously done studies and hypotheses.

\section{CONCLUSION}

The present study revealed that unhealthy interaction pattern and high level of codependency were found in the spouses of alcohol dependent patient than spouses of normal individuals. A family that has developed codependent relationships may be in need of counseling and/or treatment sometimes equal to the needs of the dependent family member.

\section{REFERENCES}

[1] Akihito, H., Kim, T., Koichi, N. (2003) Positive and Negative Effects of Social Support on the Relationship between Work Stress and Alcohol Consumption. Journal of Studies on Alcohol, 64, 874-883.

[2] Bhatti, S.R., Cuba, K.D.K., Benedicta., L.A. (1986) Validation of Family Interaction Pattern Scale. Indian Journal of Psychiatry, 28, 211-216

[3] Cermak, T.L. (1986) Diagnosis and Treating Codependency. St. paul, MN: Jhonson Institute.

[4] Cobb, S. (1976) Social support as moderator of life stress. Psychosomatic medicine, 38, 300- 374.

[5] Connors, G.J., Donovan, D.M. \& DiClemente, C.C. (2001) Substance abuse treatment and the stages of change: Selecting and planning interventions. NY: Guilford Press.

[6] Edwards, G. (1986). The alcohol dependence syndrome: A concept as stimulus to enquiry. British Journal of Addiction, 81, 171-184. 570. 
[7] Fischer, J.L., Spann, L. \& Crawford, D. (1991) Measuring codependency Alcoholism Treatment Quarterly, 8, 87-99.

[8] Frankenstein, W., Hay, W.M., Nathan. P.E. (1985): Effects of intoxication on alcoholics' marital communication and problem solving. Journal of Studies on Alcohol,46, 1-6.

[9] Goldberg, D.P., William, P. (1978) A user guide to General Health Questionnaire. Windsor, NFER-Nelson.

[10] Gorad, S.L. (1971). Communicational styles and interaction of alcoholics and their wives. Family Process, 10, 475-489.

[11] Greenleaf, J. (1984) Co-alcoholic/Para-alcoholic: who's who and what's the difference in codependency and emerging issue. Pampo Beach. Florida: Health Communication.

[12] Halford, W.K. \& Osgarby, S.M. (1993). Alcohol abuse in clients presenting with marital problems. Journal of Family Psychology, 6, 245-254.

[13] Jacob, T., Seilhamer, R.A. (1989) Alcoholism and family interaction. Recent Developments in Alcoholism 7, 129-145.

[14] Kerr, M.E. (1981) Family systems theory and therapy. In A.S. Gurman \& D.P. Kniskern (Eds.), Handbook of family therapy). New York: Brunner/Mazel, 2-26.

[15] Minuchin, Salvador (1974) Families and Family Therapy. Cambridge, MA, Harvard University Press.

[16] Moos, R.H., Finney, J.W., Cronkite, R.C. (1990). Alcoholism treatment: context, process and outcome. Oxford. Oxford University.

[17] O’Brien, P. \& Gaborit, M.(1992) Codependency: A disorder separate from chemical dependency. Journal of clinical psychology, 48, 129-136.

[18] Rychtarik, R.G., Tarnowski, K.J., St. Lawrence, J.S. (1989) Impact of social desirability response sets of the self-report of marital adjustment of alcoholics. Journal of Studies on Alcohol, 50, 24-29.

[19] Schutt, M. (1985) Wives of Alcoholics: From Codependency to Recovery. Pompano Beach, Florida : Health Communication.

[20] Singh, N.K. \& Kumar, D. (2007) Family Environment and Alcohol dependence: A Comparative Study. Indian Journal of Social Psychiatry. 23, 44-48.

[21] Singh, N.K., Bhattacharjee, D., Das, B., Kumar, M. (2009) Interaction Pattern in Indian Families with Alcohol Dependent Persons. Hongkang Journal of psychiatry. 19(3); 117120.

[22] Steinglass, P. (1980) A Life History Model of the Alcoholic Family. Family Process, 19, 211-226.

[23] Suman, L.N., Nagalakshm,i S.V. (1995) Family interaction patterns in alcoholic families. NIMHANS Journal, 13, 47-52.

[24] Tamura, T. \& Lau, A. (1984) Connectedness versus Separateness: applicability of family therapy to Japanese families. Family Process, 31, 319-340.

[25] Wolin, S.J. \& Bennet, L.A. (1984) Family rituals. Family Process, 23(3), 401- 420.

[26] Wright, P.H. \& Wright, K.D. (1991) Codependency: Addictive love, adjective relating, or both? Contemporary Family Therapy, 13, 435-454. 